\title{
ESTUDOS BRASILEIROS SOBRE O COTIDIANO NO CONTEXTO DA DOCÊNCIA: UMA REVISÃO SISTEMÁTICA
}

\author{
Andreia Martins \\ Universidade Federal de Santa Catarina \\ Camila Trindade \\ Universidade Federal de Santa Catarina \\ Maria Chalfin Coutinho \\ Universidade Federal de Santa Catarina
}

\begin{abstract}
Resumo
O presente trabalho apresenta uma pesquisa de revisão sistemática em estudos brasileiros sobre a temática do cotidiano em contextos de docência, mais especificamente, sobre as abordagens teórico-metodológicas utilizadas nos mesmos. Foram selecionadas publicações indexadas nas bases de dados Portal de Periódicos da CAPES/MEC e no Scielo, no período de 2006 a 2015. Apesar da diversidade teórica de perspectivas sobre o cotidiano, verificou-se que os estudos produzidos no cenário brasileiro se ancoram nas teorias sobre o cotidiano de Michel de Certeau e de Agnes Heller. Em relação aos aspectos metodológicos os estudos analisados evidenciaram o uso de vários instrumentos de pesquisa, sendo a entrevista e a observação, as técnicas mais utilizadas. No que concerne à análise das informações em estudos brasileiros sobre o cotidiano, no contexto da docência, observou-se que a maioria dos estudos não reportam de forma detalhada como procederam a apreciação e o tratamento de seus dados.
\end{abstract}

Palavras-chave: cotidiano; docência; métodos de pesquisa.

\section{BRAZILIAN STUDIES ABOUT THE DAILY ROUTINE IN THE CONTEXT OF TEACHING: A SYSTEMATIC REVIEW}

\begin{abstract}
The present work presents a systematic review of Brazilian studies about daily life in teaching contexts, more specifically, on the theoretical and methodological approaches used in them. Indexed publications in the CAPES / MEC Periodical Portal databases and in Scielo were selected, from 2006 to 2015. Despite the theoretical diversity of perspectives on daily life, it was verified that the studies produced in the Brazilian scenario are anchored in theories about daily life of Michel de Certeau and Agnes Heller. Regarding the methodological aspects, the studies analyzed evidenced the use of several research instruments; interview and observation being the most used techniques. Regarding to the analysis of information in Brazilian studies on daily life, in the context of teaching, it was observed that most of the studies do not mention in detail how they assessed and processed their data.
\end{abstract}

Keywords: daily life; teaching; search methods. 


\title{
INVESTIGACIONES BRASILEÑAS ACERCA DE LO COTIDIANO EN EL CONTEXTO DE LA DOCENCIA: UNA REVISIÓN SISTEMÁTICA
}

\begin{abstract}
Resumen
El siguiente trabajo presenta una investigación sistemática sobre estudios brasileños acerca de la temática de lo cotidiano en contextos de docencia, de forma más específica acerca de los aportes teórico-metodológicos utilizados en los mismos. Fueron seleccionadas publicaciones indexadas en las bases de datos "Portal de Periódicos da CAPESC/MEC" y en el "Scielo", en el período entre 2006 hasta 2015. A pesar de la diversidad teórica de perspectivas acerca de lo cotidiano, se pudo verificar que los estudios producidos en el escenario brasileño se anclan en las teorías acerca de lo cotidiano de Michel de Certeau y de Agnes Heller. Con relación a los aspectos metodológicos, los estudios analizados ponen en evidencia el uso de varios instrumentos de investigación, en los cuales la entrevista y la observación son las técnicas más utilizadas. Con respecto a los análisis de las informaciones en estudios brasileños acerca de lo cotidiano en el contexto de la docencia, se pudo observar que la mayor cantidad de estudios no hacen mención con demasiados detalles a la forma como procedieron en la apreciación y al tratamiento de sus datos.
\end{abstract}

Palabras Clave: cotidiano; docencia; métodos de investigación.

\section{INTRODUÇÃO}

A vida cotidiana pode ser compreendida a partir dos momentos vivenciados dia a dia pelos sujeitos, momentos esses que são marcados por repetições, regras, rotinas e rituais (Martins, 1998). Já, em relação ao discurso científico, Pais (2009) aponta duas perspectivas sobre o cotidiano: uma direcionada aos acontecimentos que rompem com a rotina e a monotonia do dia a dia e outra voltada para a esfera privada do cotidiano, denotando abrigo, aconchego, amparo e proteção.

Neste sentido, os estudos sobre a vida cotidiana se apresentam como uma significativa tarefa para os pesquisadores, tendo em vista a complexidade e a multiplicidade que constitui esse campo de estudo, além do fato de que "É na vida cotidiana que a História se desvenda ou se oculta" (Martins, 2015, p. 12). Dessa maneira, compreende-se, segundo Azanha (1992), que as investigações sobre o cotidiano promovem a produção de conhecimentos frente os diversos modos da vida cotidiana, procurando estabelecer as conexões e o desenvolvimento desses modos, para assim entender as ações aparentemente destoadas da desordem empírica.

Diante disso, deve-se acrescentar que nos estudos relacionados com a temática do cotidiano é possível observar uma variedade de abordagens teóricometodológicas, oriundas das mais diversas ciências sociais. Entre essas abordagens, Tedesco (1999) e Pais (2009) discorrem sobre o formismo, o interacionismo, a fenomenologia e o marxismo.

A perspectiva do formismo se propõe a evidenciar os aspectos da vida cotidiana que são despercebidos, na maioria das vezes, pela sociologia tradicional. Entre os seus principais expoentes, destaca-se os autores Georg Simmel, Georges Balandier e Michel Maffesoli. Para esta perspectiva o cotidiano é constituído pelas micro-ações dos indivíduos e a percepção da realidade é carregada de simbolismo, como uma pintura de estilo impressionista (Pais, 2009). 
Para Maffesoli (1988) o formismo está implicado em uma nova maneira de refletir sobre dois conceitos antigos, mas presente no debate científico - o singular e o universal. A maneira formista de pensar sobre a existência humana vai em direção a um modo globalizante de refletir sobre esses conceitos, jamais privilegiando uma análise isolada dos objetos, mas sim contextualizado todas as variáveis que os constituem. Desse modo, "[...] a essência do ser/estar-junto-com e a existência concreta formam um misto intrincado cujos diversos elementos componentes será conveniente apreciar. [...] o formismo é, antes de mais nada, um pensamento da globalidade" (p. 121-122).

Os estudos na Universidade de Chicago, nos Estados Unidos na década de 1960, sob a orientação de Erving Goffman, Harold Garfinkel e Aaron Cicourel deram início ao interacionismo, o qual destaca que as estruturas e as organizações dão possibilidades para o incremento de todas as ações sociais, mas não as definem (Tedesco, 1999). Os interacionistas Berger e Luckmann (2011, p. 36) discorrem que: O mundo da vida cotidiana "[...] é um mundo que se origina no pensamento e na ação dos homens comuns, sendo afirmado como real por eles".

Para a perspectiva da fenomenologia, as significações constituídas subjetivamente pelos sujeitos em sua ação social são importantes motes de análises da sociologia da vida cotidiana, visto que sem o atendimento dos componentes subjetivos, os encadeamentos objetivos se apresentam enquanto descrições errôneas da realidade. Os representantes dessa abordagem são Edmund Husserl e Alfred Schütz (Tedesco, 1999).

Já, o marxismo enfatiza que a vida cotidiana pode segmentar-se e esvaecerse por organizações e ações reguladoras, como o trabalho, a cultura, o ócio e o lazer, tendo como foco o sujeito e a rotina. Entre os autores desta perspectiva, estão Henri Lefebvre e Agnes Heller (Pais, 2009; Tedesco 1999).

Diante da diversidade de teorias sobre o cotidiano, o presente artigo tem como objetivo apresentar os resultados de uma pesquisa de revisão sistemática de literatura realizada no Portal de Periódicos da CAPES/MEC e no Scielo. A opção por essa modalidade de pesquisa, se deu em virtude de que a mesma possibilitou que fossem mapeadas as abordagens teórico-metodológicas utilizadas nos estudos desenvolvidos no Brasil referente ao cotidiano em contextos de docência, produzidos nos últimos nove anos. Para isso a pergunta norteadora do trabalho foi: quais são as abordagens teórico-metodológicas utilizadas nos estudos brasileiros sobre cotidiano em contextos de docência?

A revisão sistemática foi concretizada respeitando respectivamente as seguintes etapas: especificação do problema (construção da pergunta norteadora da pesquisa), pesquisa dos trabalhos, avaliação dos estudos e, por fim, análise, interpretação e apresentação dos resultados.

A ambiência da docência foi adotada em função do fato de que a primeira e segunda autora, realizam suas pesquisas de pós-graduação na área da docência, mais especificamente sobre o cotidiano do trabalho docente. Neste sentido, 
observou-se a necessidade de investigar o que as publicações brasileiras nos últimos anos, vêm produzindo no campo temático do cotidiano nos contextos de docência.

Logo, no decorrer do presente texto serão relatados os procedimentos e os resultados desta pesquisa, sendo que para isso o mesmo foi organizado em quatro seções: a seguinte que irá relatar os procedimentos metodológicos da pesquisa, na sequência serão apresentados os resultados e discussão do estudo e por fim as considerações finais.

\section{MÉTODO}

Foi realizada uma pesquisa de revisão sistemática, mais especificamente, na modalidade de revisão integrativa. Segundo Aliane, Mamede e Furtado (2011) a revisão sistemática tem como objetivo evidenciar um questionamento, sendo que para isso ela pressupõe a utilização de métodos que distinguem e avaliam criteriosamente estudos pertinentes ao tema pesquisado.

Quanto à pesquisa dos trabalhos, foi realizada uma busca eletrônica nas bases de dados do Portal de Periódicos da CAPES/MEC (http://www.periodicos.capes.gov.br/) e no Scielo (www.scielo.br), por meio do cruzamento entre os seguintes descritores: cotidiano/professores, cotidiano/trabalho docente, cotidiano/professores universitários, cotidiano/docentes universitários, cotidiano/professores ensino fundamental, cotidiano/docência e cotidiano/docentes.

Acrescente-se que o estudo considerou os trabalhos produzidos referentes às temáticas em questão publicados no período de 2006 a 2015. Tendo como critérios de inclusão trabalhos: a) cadastrados e publicados nas bases selecionadas; 2) estudos brasileiros; 3 ) com a temática de cotidiano na perspectiva do trabalho docente; 4) estudos com interface entre a Psicologia e a Educação. Os critérios de exclusão foram os seguintes: 1) estudos sobre cotidiano especificamente relacionados aos discentes; 2 ) estudos realizados fora do período especificado e 3 ) estudos que não foi possível ter acesso ao trabalho completo.

Com a finalidade de sistematizar os estudos selecionados para a catalogação e análise foi desenvolvido um formulário estruturado a partir dos respectivos itens: descritores utilizados, identificação do periódico, título do artigo, objetivos; autores; ano de publicação; tipo de trabalho; teoria e método utilizado; resultados e considerações finais.

A partir dos critérios acima especificados, a realização da pesquisa apontou para a existência de vinte e cinco publicações, sendo que destas foram encontradas doze dissertações, sete teses e um artigo totalizando vinte trabalhos no Portal de Periódicos da CAPES/MEC e cinco artigos na base de dados da Scielo. O fluxograma a seguir, sintetiza e exemplifica as estratégias e os resultados encontrados na pesquisa. 


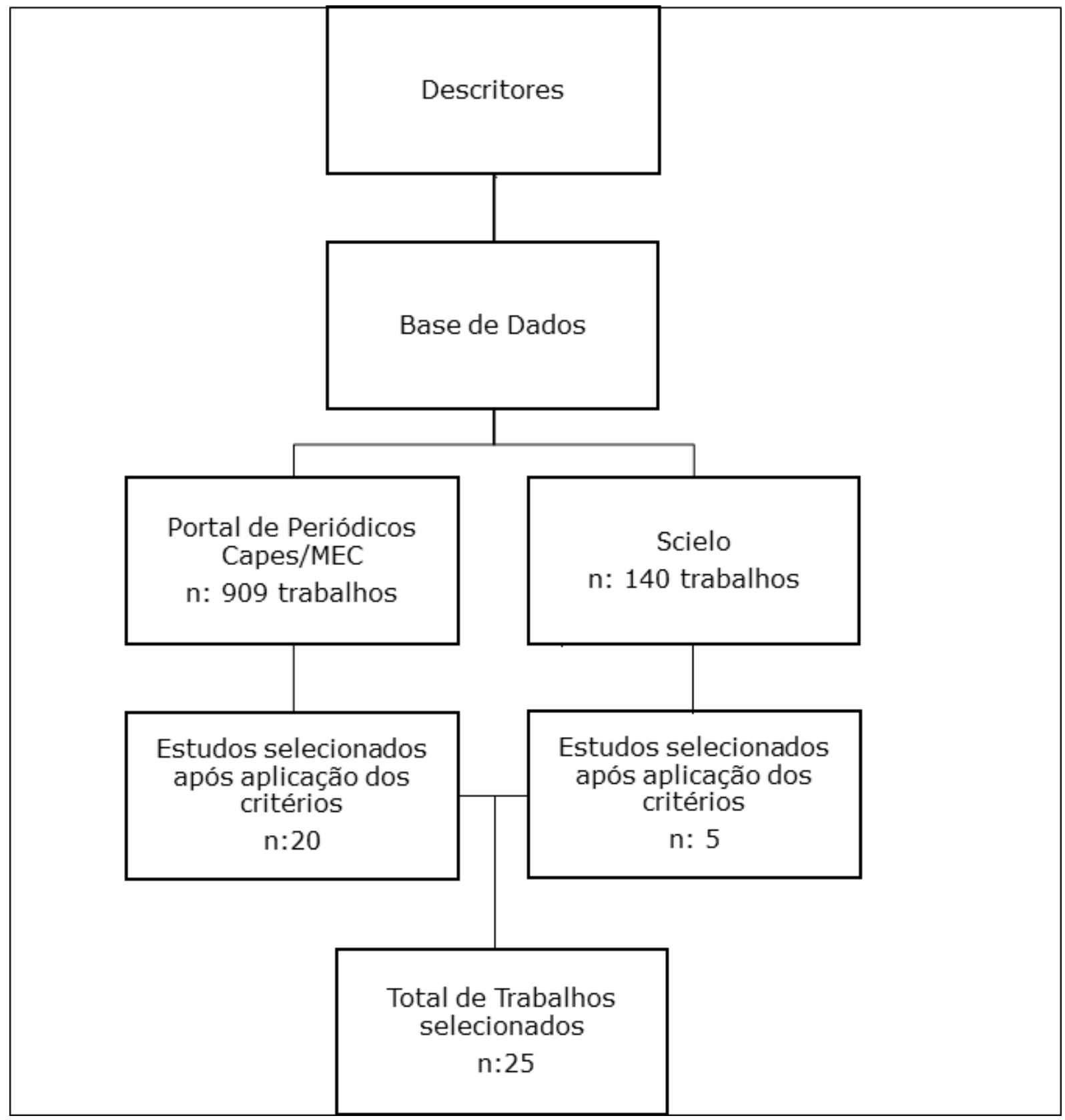

Figura 1. Fluxograma das estratégias e resultados da pesquisa na base de dados CAPES/MEC e Scielo.

\section{RESULTADOS}

Pôde-se observar nas análises dos estudos relacionados ao cotidiano que, entre o período de 2006 a 2015, os anos nos quais se realizaram o maior número de publicações foram em 2009 e 2012, sendo publicados respectivamente cinco trabalhos em cada ano. Nos demais períodos, o número de publicações foram os seguintes: três estudos em 2006, três em 2007, três em 2008, três em 2010, dois em 2013 e um em 2015. 
As análises foram iniciadas contabilizando o número de estudos relacionados ao cotidiano publicados em cada ano no período de 2006 a 2015. De 2006 a 2008 foram publicados três estudos por ano, em 2009 o número de publicações foi cinco, em 2010 foram novamente três, não houve artigos focados na temática em questão no ano de 2011, em 2012 foram publicados cinco textos, em 2013 dois estudos, em 2014 também não foram publicados estudos sobre o tema. Esse levantamento sugere uma irregularidade nas publicações sobre cotidiano no contexto da docência, com destaque para 2009 e 2012, anos com maior número de publicações.

Quanto à área de conhecimento em que as pesquisas foram produzidas evidenciou-se que grande parte desses trabalhos foram desenvolvidos em Programas de Pós-Graduação em Educação ou em Faculdades de Educação, totalizando vinte estudos. Deve-se destacar que outros estudos foram produzidos em Programa de Pós-Graduação em História (um estudo), em Programa de PósGraduação em Psicologia (dois estudos), em Programa de Pós-Graduação em Geografia (um estudo) e no Programa de Pós-Graduação em Ciências e Letras (um estudo). Os docentes participantes dos trabalhos analisados em sua totalidade atuam na Educação Básica, especialmente no Ensino Fundamental.

Em relação às teorias utilizadas nos estudos, observou-se que em dezessete trabalhos foram utilizados a perspectiva de Michel Certeau, especialmente suas contribuições advindas da obra A invenção do Cotidiano - 1. Artes de Fazer (2008) e outros cinco trabalhos fizeram uso da Teoria do Cotidiano de Agnes Heller desenvolvida principalmente na obra O cotidiano e a história (2014). Além destes, um trabalho realizou uma articulação entre Michel de Certeau e José Pais, outro estudo abordou a perspectiva da Sociologia do Cotidiano de Michel Maffesoli e, por fim, outro trabalho adotou os conceitos de vida cotidiana na perspectiva de Alfred Schutz.

Desta maneira, para melhor visualização das dezessete pesquisas desenvolvidas na perspectiva de Certeau, a seguir, na Tabela 1, apresenta-se os autores, os participantes do estudo, os instrumentos e as técnicas de análise utilizadas em cada estudo.

Tabela 1. Caraterização dos estudos na abordagem de Michel de Certeau

\begin{tabular}{cccc}
\hline Autores & Participantes & Instrumento & Análise \\
\hline Guedes-Pinto e & Professores do & Não deixa claro & Não evidencia \\
Fontana (2006) & Ensino Básico & & \\
Luchese e & Professores do & Entrevistas e análise \\
Grazziotin & Ensino Básico & dos documentos de & Não evidencia \\
$(2015)$ & & acervos & \\
\hline
\end{tabular}




\begin{tabular}{|c|c|c|c|}
\hline Silva (2012) & $\begin{array}{l}\text { Professores do } \\
\text { Ensino Básico }\end{array}$ & $\begin{array}{l}\text { Observações, } \\
\text { questionários e } \\
\text { entrevistas }\end{array}$ & Não evidencia \\
\hline Sene (2010) & $\begin{array}{l}\text { Professores do } \\
\text { Ensino Básico }\end{array}$ & Entrevistas & $\begin{array}{l}\text { Análise } \\
\text { Temática }\end{array}$ \\
\hline Mielke (2010) & $\begin{array}{l}\text { Professores do } \\
\text { Ensino Básico }\end{array}$ & $\begin{array}{c}\text { Observações e } \\
\text { análise documental. }\end{array}$ & Não evidencia \\
\hline Bezerra (2009) & $\begin{array}{l}\text { Professores do } \\
\text { Ensino Básico }\end{array}$ & $\begin{array}{l}\text { Entrevista, } \\
\text { observação, análise } \\
\text { documental. }\end{array}$ & Não evidencia \\
\hline Annibal (2009) & $\begin{array}{l}\text { Professores do } \\
\text { Ensino Básico }\end{array}$ & Entrevistas & Narrativa \\
\hline Carreri (2007) & $\begin{array}{l}\text { Professores do } \\
\text { Ensino Básico }\end{array}$ & Entrevistas & Não evidencia \\
\hline Corrêa (2009) & $\begin{array}{l}\text { Professores do } \\
\text { Ensino Básico }\end{array}$ & $\begin{array}{c}\text { Observações, } \\
\text { documentos, diário } \\
\text { de campo, } \\
\text { entrevistas. }\end{array}$ & Narrativa \\
\hline $\begin{array}{c}\text { Aragão e } \\
\text { Freitas (2012) }\end{array}$ & $\begin{array}{l}\text { Professores do } \\
\text { Ensino Básico }\end{array}$ & Texto Teórico & Bibliográfico \\
\hline Adami (2009) & $\begin{array}{l}\text { Professores do } \\
\text { Ensino Básico }\end{array}$ & $\begin{array}{l}\text { Entrevista, } \\
\text { observação, } \\
\text { participação. }\end{array}$ & Não evidencia \\
\hline $\begin{array}{c}\text { Alvarenga } \\
\text { (2008) }\end{array}$ & $\begin{array}{l}\text { Professores do } \\
\text { Ensino Básico }\end{array}$ & $\begin{array}{l}\text { Questionário, diário } \\
\text { de uso do tempo, } \\
\text { entrevista e diário } \\
\text { de campo. }\end{array}$ & Não evidencia \\
\hline $\begin{array}{l}\text { Shiohara } \\
(2009)\end{array}$ & $\begin{array}{l}\text { Professores do } \\
\text { Ensino Básico }\end{array}$ & $\begin{array}{c}\text { Registros de } \\
\text { fragmentos do } \\
\text { cotidiano do } \\
\text { trabalho da autora } \\
\text { enquanto } \\
\text { professora, fez uso } \\
\text { de fotografia. }\end{array}$ & $\begin{array}{c}\text { Crítica } \\
\text { Genética } \\
\text { (Cecília } \\
\text { Salles), } \\
\text { Gabriel } \\
\text { Junqueira } \\
\text { Filho } \\
\text { (linguagens } \\
\text { geradoras } \\
\text { educação } \\
\text { infantil), } \\
\text { Bakhtin } \\
\text { (linguagem) }\end{array}$ \\
\hline
\end{tabular}




\begin{tabular}{|c|c|c|c|}
\hline Silva (2012) & $\begin{array}{l}\text { Professores do } \\
\text { Ensino Básico }\end{array}$ & $\begin{array}{l}\text { Caderno de recados, } \\
\text { contrato de estágio } \\
\text { e plano de ensino. }\end{array}$ & Bakhtin \\
\hline $\begin{array}{c}\text { Camargo } \\
(2013)\end{array}$ & $\begin{array}{l}\text { Professores do } \\
\text { Ensino Básico }\end{array}$ & $\begin{array}{c}\text { Observação / auto- } \\
\text { observação }\end{array}$ & Narrativa \\
\hline Lopretti (2007) & $\begin{array}{l}\text { Professores do } \\
\text { Ensino Básico }\end{array}$ & $\begin{array}{l}\text { Diário de campo, } \\
\text { áudio-gravações, } \\
\text { análise de } \\
\text { documentos da } \\
\text { escola }\end{array}$ & $\begin{array}{l}\text { Paradigma } \\
\text { Indiciário } \\
\text { de Carlo } \\
\text { Ginzburg }\end{array}$ \\
\hline Pierini (2007) & $\begin{array}{l}\text { Professores do } \\
\text { Ensino Básico }\end{array}$ & Observações & Não evidencia \\
\hline
\end{tabular}

Com relação à caracterização dos estudos de Michel de Certeau (Tabela 1), apenas duas pesquisas não foram realizadas em Programas de Pós-Graduação em Educação, dessas uma no Programa de Pós-Graduação em História Social e outra no Programa de Pós-Graduação em Geografia.

Na sequência, na Tabela 2, apresenta-se os cinco estudos ancorados na perspectiva de Agnes Heller, desenvolvidos principalmente na obra "O cotidiano e a história" (2014).

Tabela 2. Caraterização dos estudos na abordagem de Agnes Heller

\begin{tabular}{|c|c|c|c|}
\hline Autores & Participantes & Instrumento & Análise \\
\hline $\begin{array}{c}\text { Lara, } \\
\text { Tanamachi e } \\
\text { Junior (2006) }\end{array}$ & $\begin{array}{l}\text { Professores do } \\
\text { Ensino Básico }\end{array}$ & $\begin{array}{c}\text { Entrevista, } \\
\text { observações, } \\
\text { análise } \\
\text { documental. }\end{array}$ & $\begin{array}{l}\text { Os critérios de } \\
\text { análise foram } \\
\text { definidos pelos } \\
\text { autores. }\end{array}$ \\
\hline $\begin{array}{l}\text { Zibetti e Souza } \\
\text { (2010) }\end{array}$ & $\begin{array}{l}\text { Professores do } \\
\text { Ensino Básico }\end{array}$ & $\begin{array}{c}\text { Observação } \\
\text { participante, } \\
\text { entrevistas e } \\
\text { análise documental } \\
\text { (etnografia). }\end{array}$ & Não específica \\
\hline Horibe (2012) & $\begin{array}{l}\text { Professores do } \\
\text { Ensino Básico }\end{array}$ & $\begin{array}{l}\text { Observação, } \\
\text { análise } \\
\text { documental } \\
\text { (Etnografia). }\end{array}$ & $\begin{array}{c}\text { A análise se deu a } \\
\text { partir da } \\
\text { contribuição de } \\
\text { autores críticos da } \\
\text { Educação e } \\
\text { Psicologia Escolar }\end{array}$ \\
\hline Silva (2008) & $\begin{array}{l}\text { Professores do } \\
\text { Ensino Básico }\end{array}$ & $\begin{array}{c}\text { Análise } \\
\text { documental. }\end{array}$ & $\begin{array}{l}\text { Os critérios de } \\
\text { análise foram }\end{array}$ \\
\hline
\end{tabular}




\begin{tabular}{|c|c|c|c|}
\hline & & & $\begin{array}{c}\text { definidos pela } \\
\text { autora }\end{array}$ \\
\hline $\begin{array}{l}\text { Oliveira } \\
(2012)\end{array}$ & $\begin{array}{l}\text { Professores do } \\
\text { Ensino Básico }\end{array}$ & $\begin{array}{l}\text { Diário de campo, } \\
\text { observações, } \\
\text { questionário e } \\
\text { entrevista } \\
\text { (etnografia). }\end{array}$ & $\begin{array}{c}\text { Análise de } \\
\text { Conteúdo Bardin }\end{array}$ \\
\hline
\end{tabular}

Entre os cinco estudos desenvolvidos na perspectiva de Agnes Heller (Tabela 2), dois foram desenvolvidos em Programas de Pós-Graduação em Educação e um em Programa de Pós-Graduação em Psicologia. Os demais trabalhos são artigos, sendo um publicado em revista de Psicologia e outro em uma revista da área de Educação.

Quanto aos instrumentos utilizados para a produção dos dados das pesquisas, quatorze trabalhos enfatizaram que fizeram uso de entrevistas com professores e onze trabalhos destacaram a realização de observações no cotidiano escolar, especialmente, no que se refere à atividade de trabalho do professor. Foram mencionados ainda como instrumentos de coleta de dado, o uso de questionários em quatro estudos, a revisão bibliográfica em um estudo, a observação participante em dois estudos, a análise documental em dez estudos, a fotografia em um estudo, o diário de uso do tempo em dois estudos, o diário de campo em três estudos e a auto-observação em um estudo.

Sobre as análises dos dados das pesquisas, doze estudos não evidenciaram ou não especificaram o procedimento utilizado e seis trabalhos desenvolveram critérios próprios de análises dos resultados. Foram mencionados, ainda, a utilização na análise dos dados de princípios da pesquisa narrativa em dois estudos, da análise temática em um estudo, da crítica genética em um estudo, da análise indiciária em um estudo, da análise microestrutural e macroestrutural em um estudo, da perspectiva de Bakhtin em dois estudos e Bardin em um estudo. 0 pacote estatístico SPSS (Statiscal Package for Social Science) foi utilizado em um estudo.

No que se refere aos métodos utilizados nos estudos, oito estudos não descreveram detalhadamente como conduziram a apreciação de suas pesquisas. Os demais trabalhos utilizaram: a semiótica de Bakhtin em um estudo, as proposições da história oral em um estudo, a etnografia em seis estudos, a pesquisa qualitativa em seis estudos, a teoria das mediações em um estudo, o método narrativo em três estudos, a pesquisa ação em dois estudos, o materialismo histórico dialético em um estudo e o método quantitativo também em um estudo. 


\section{DISCUSSÃO}

Visando investigar quais são as principais abordagens teórico-metodológicas utilizadas nos estudos brasileiros sobre o cotidiano nos contextos de docência, foi realizado um estudo de revisão sistemática nas bases de dados do Portal de Periódicos da CAPES/MEC e do Scielo, no período de 2006 a 2015. A partir disso, pode-se constatar que embora exista uma diversidade de abordagens teóricometodológicas nos estudos sobre o cotidiano, observou-se algumas convergências nessas produções, visto que grande parte dos estudos são ancorados nas teorias de Michel de Certeau e de Agnes Heller. Entre os instrumentos para levantamento de informações utilizados se destacam as observações e as entrevistas, e os procedimentos de análise dos dados, quando apresentados, não detalham como foram realizados.

Como já mencionado anteriormente, apesar da variedade de abordagens do cotidiano, a perspectiva de Michel de Certeau foi a mais utilizada, totalizando dezessete estudos, seguido da teoria do cotidiano de Agnes Heller empregada em cinco trabalhos. Michel de Certeau (2008) enfatiza o estudo das minúcias do cotidiano articuladas com as ações dos sujeitos, ou mais especificamente, as maneiras de fazer que "constituem as mil práticas pelas quais usuários se reapropriam do espaço organizado pelas técnicas da produção sociocultural" (p.41). Já Agnes Heller (2014), ao analisar as relações que se estabelecem entre os seres humanos e a sua vida cotidiana, afirma que estes já nascem inseridos em relações cotidianas e que o seu desenvolvimento está relacionado, justamente com a construção de "todas as habilidades imprescindíveis para a vida cotidiana da sociedade (camada social) em questão" (p.33).

Dessa maneira, Heller (2014) descreveu alguns modos de ações que constituem e dão forma à vida cotidiana das pessoas, entre esses: a heterogeneidade, a hierarquia, a homogeneidade, a alienação, a espontaneidade, a probabilidade, os preconceitos, os papéis, o tempo, o espaço, entre outros.

Quanto aos aspectos metodológicos, observa-se na Tabela 1 (estudos na perspectiva de Certeau) que as pesquisas de Annibal (2009), Carreri (2007) e Sene (2010) empregaram somente entrevistas para a coleta de dados. De outro modo, os estudos de Luchese e Grazziotin (2015), Silva (2012), Bezerra (2009), Corrêa (2009) e Adami (2009) usaram entrevistas aliadas com observações do cotidiano escolar, análises documentais, diário de campo e diário de uso do tempo. E os estudos de Mielke (2010), Shiohara (2009), Silva (2012), Camargo (2013) e Pierini (2007) conduziram suas pesquisas por meio de observações, autoobservações, análise documental e fotografias, não utilizando entrevistas para o desenvolvimento de seus trabalhos.

Desse modo, verifica-se que as entrevistas foram utilizadas em grande parte dos estudos, ora como único recurso, ora relacionadas com outras técnicas para a investigação do cotidiano. De acordo com Bell (2008), uma das principais 
vantagens da entrevista é sua adaptabilidade e sua indicação para estudos que desejam aprofundar respostas e investigar motivos e sentimentos, possibilitando ao entrevistado falar sobre o tema em questão sem se prender no questionamento.

Nesse sentido, existem diversas modalidades de entrevistas, com diferentes denominações e orientações. A entrevista compreensiva, por exemplo, segundo Zago (2003, p. 295) "[...] não tem uma estrutura rígida, isto é, as questões previamente definidas podem sofrer alterações conforme o direcionamento que se quer dar à investigação". Já Aguiar e Ozella (2013) indicam as entrevistas recorrentes, as quais oportunizam a dialógica entre pesquisador e pesquisado, dessa maneira entre um encontro e outro, é indicado que o pesquisador realize uma leitura prévia da transcrição da entrevista com a finalidade de minimizar as possíveis dúvidas e aprofundar a comunicação entre ambos.

Cabe pontuar que o emprego de variados instrumentos para o levantamento de informações possibilita ao pesquisador uma vasta amplitude do conhecimento e da apreensão do cotidiano. Como Pais (2012), entendemos que: "Para quem estuda o cotidiano atual, a análise das fontes escritas terá inevitavelmente de se complementar com a análise das fontes audiovisuais" (p. 155), pois essas "[...] são, acima de tudo, fontes de inspiração, ou melhor, fontes de modelação de estilos de vida ritualizados, massificados, banalizados" (Pais, 2012, p. 164).

Mais ainda, compreendemos que o cruzamento com diversos instrumentos de pesquisas, como fontes imagéticas, documentais, observações, entrevistas recorrentes, entre outros, auxiliam o pesquisador a acessar o cotidiano em seus aspectos fugidios e na minuciosidade das ações diárias. Ao analisar a arte do fraco, Certeau (2008, p. 38) pontua que, para além da cultura dominante, existem outras práticas culturais invisíveis e astuciosas produzidas pelos dominados no cotidiano como "mil maneiras de caça não autorizada" (Certeau, 2008, p.38). O emprego de múltiplas ferramentas para o levantamento das informações permitiria vislumbrar melhor as práticas cotidianas astuciosas e, assim, possibilitaria um refinamento da análise das diversas atividades que compõem esse campo de estudo, especialmente no campo da docência.

Defendemos aqui o uso de instrumentos diversos de pesquisa para desvendar as táticas ou modos de ação sutis empregados por quem não detém o poder, ou como coloca Certeau (2008, p. 46) "não pode contar com um próprio". Em contrapartida, na perspectiva desse autor, só quem tem poder é capaz de produzir e impor estratégias. Ou melhor, "... a tática é determinada pela ausência de poder, assim como a estratégia é organizada pelo postulado de um poder" (Certeau, 2008, p. 95). Se as táticas são exercidas de modo sutil e se aproveitam de ocasiões para obter alguns ganhos, aproveitando as falhas de quem tem poder, por meio de práticas não autorizadas, o pesquisador precisa apurar o olhar para identificar também as ações fugidias e não apenas a produção dominante.

Com relação aos procedimentos metodológicos, especificamente aos instrumentos de pesquisa, verifica-se na Tabela 2, onde consta os trabalhos 
desenvolvidos a partir da perspectiva de Heller, que os estudos de Zibetti e Souza (2010), Horibe (2012) e Oliveira (2012) utilizaram a etnografia para desenvolver suas pesquisas. Lara et al. (2006) não empregaram especificamente a pesquisa etnográfica em seus estudos, apesar de mencionarem o uso da técnica de observação. Assim, como Silva (2008), que aponta a dinâmica de funcionamento do seu objeto de estudo ancorada, entre outros instrumentos, na observação. Portanto, todos os autores fazem uso direta ou indiretamente da técnica de observação, contudo alguns explicitam se tratar de etnografia.

Conforme discorrem Sato e Souza (2001) "A abordagem etnográfica tem se mostrado importante instrumental no sentido de compreender como as pessoas coletivamente constroem e dinamizam processos sociais, como a subjetividade se expressa, como atribuem significado às situações sociais" (p. 29). Logo, a pesquisa etnográfica possibilita uma maior interação do pesquisador com os participantes de seu estudo, mais ainda, com os modos de interações sociais vivenciados pelos sujeitos, propiciando, em função de suas particularidades, acessar os vários modos de ação da vida cotidiana discutidos por Heller (2014).

Outra característica importante da pesquisa etnográfica é a apresentação da coleta e análise de dados de uma forma imbricada, relacional e apresentada sem dicotomias (Sato \& Souza, 2001). A referida particularidade da pesquisa etnográfica vem ao encontro do que constatamos na Tabela 2, pois somente Oliveira (2012) descreveu a técnica utilizada para a análise dos dados, os demais estudos não mencionaram as estratégias utilizadas.

\section{CONSIDERAÇÕES FINAIS}

Ao término desse estudo, pôde-se constatar uma irregularidade nas publicações sobre cotidiano no contexto da docência, apresentando avanços e recuos na produção, com destaque para 2009 e 2012, anos com maior número de publicações. A partir desta revisão, apenas 25 trabalhos foram identificados, mostrando-se como um número bastante tímido, considerando o período do tempo abordado no presente estudo. Coutinho, Oliveira e Sato (2016) destacam que os estudos do cotidiano têm avançado nas pesquisas brasileiras, mas observam que ainda falta um maior esforço de teorização sobre essa temática no campo da Psicologia.

Destaca-se, conforme as análises das pesquisas, que os sujeitos dos trabalhos em questão são essencialmente professores do ensino básico. Este cenário de produção das pesquisas sinaliza a necessidade do desenvolvimento de trabalhos empíricos relacionados com o cotidiano de professores dos outros níveis de ensino.

Grande parte dos trabalhos tem sido produzido na área da Educação e poucos na área da Psicologia. Conforme Coutinho et al. (2016) é raro encontrar no campo da Psicologia obras com direcionamento de estudos no campo do 
cotidiano. Contudo, o cotidiano seria o espaço por excelência de investigação da Psicologia Social, em função de possibilitar ao pesquisador apreender as relações de poder, as interações sociais e os significados das ações realizadas diariamente pelos trabalhadores (Coutinho et al., 2016). Desse modo, os estudos sobre o cotidiano, especialmente em contextos educativos, podem contribuir para uma melhor compreensão de como os docentes constroem suas relações de trabalho e, dialeticamente, produzem os sentidos de suas atividades laborais.

Com relação às abordagens, apesar da grande diversidade teórica de perspectivas sobre o cotidiano na ambiência da docência, verificou-se nessa revisão sistemática que as publicações científicas têm se apoiado principalmente em autores clássicos, com destaque para as obras de Michel de Certeau e Agnes Heller. De acordo com Levigard e Barbosa (2010, p. 88) "As ideias de Agnes Heller, Henri Lefebvre e Michel de Certeau trazem contribuições fundamentais para a reflexão sobre a constituição dos sujeitos sociais, sobre a questão do planejamento e gestão dos espaços sociais ...".

Segundo Patto (1993) a presença de Agnes Heller em pesquisas na área da Psicologia Educacional brasileira está relacionada aos obstáculos de cunho teórico e metodológico que foram se desenvolvendo neste campo do conhecimento desde a década de 1980. Assim, entende-se que a visão helleriana sobre a vida cotidiana possibilitou o desenvolvimento de pesquisas no âmbito das instituições educacionais a partir de um olhar que integra as relações macro e microssociais, inseridas em um processo histórico, situando a escola dentro da estrutura social de classes, característica da sociedade capitalista. Como enfatiza Patto (1993, p. 120), "o estudo da escola estava a requerer uma teoria marxista que desse conta da participação das pessoas, dos indivíduos, dos sujeitos na vida social".

Já pesquisar o cotidiano no âmbito educacional, a partir do olhar de Michel de Certeau, alude a observar as "artes de fazer" de docentes e alunos no cotidiano escolar, ao efetivarem as "táticas da arte do fraco" em um contexto dominado pelas "estratégias" das políticas educacionais. Desse modo, torna-se possível desvelar o camuflado, o implícito da trivialidade de cada dia, revelando as astúcias cotidianas e as "maneiras de fazer", como nomeia Certeau (1998, p. 41), as formas usadas para driblar a manipulação e a racionalização estratégica de quem detém o poder. Conforme Duran (2007, p. 117) as pesquisas sob o olhar de Certeau (1998) auxiliam para apreender "às invenções dos professores e dos alunos, as formas como interpretam as políticas educacionais, as suas maneiras de fazer - a pesquisa das práticas - a lógica do cotidiano".

Em relação aos aspectos metodológicos, pôde-se verificar uma variedade de perspectivas utilizadas pelos estudos analisados nessa revisão, por exemplo, desde as contribuições Etnográficas, até as Teorias das Mediações. Deve-se acrescentar ainda, que alguns trabalhos não mencionaram explicitamente como desenvolveram suas pesquisas. Contudo, conforme ressalta Spink (2008, p.72) "ser um pesquisador no cotidiano se caracteriza frequentemente por conversas 
espontâneas em encontros situados", não havendo a imprescindibilidade da utilização de métodos engessados e operacionalmente cumpridos de forma rígida.

Observou-se que os estudos analisados na presente revisão, empregam uma diversidade de instrumentos nas produções e análises dos dados das pesquisas. Desse modo, cabe ressaltar, que o uso da entrevista aliada a outros instrumentos de pesquisa, tais como, observações, diário de campo, fotográficas etc., possibilita uma melhor compreensão analítica do fenômeno pesquisado. Como diz Pais (2009, p. 155) "Há que se entender o cotidiano com ambos os canais de recepção: o auditivo e o visual. Esse entendimento obriga o investigador a recorrer a fontes audiovisuais que contemporaneamente se abundam".

Contudo, entende-se que mais importante do que a variedade de instrumentos utilizados em pesquisas no/do cotidiano é a forma como o pesquisador irá conduzir seu estudo. Com enfatiza Spink (2008, p.71) o "cotidiano se compõe de milhares de micro lugares; não é um contexto eventual ou um ambiente visto como pano de fundo. Os micro lugares, tal como os lugares, somos nós; somos nós que os construímos". Logo, destaca-se a necessidade das discussões e reflexões sobre as abordagens teórico-metodológicas que orientam a produção científica. Sejam essas, em relação a qualquer temática de investigação e no caso da presente discussão sobre as pesquisas do cotidiano no contexto da docência, visto que é por meio das abordagens teórico-metodológicas que se expressam as formas e os conteúdos sobre a prática de pesquisar.

\section{DECLARAÇÃO DE CONFLITOS DE INTERESSE}

Não há conflito de interesse de ordem pessoal, comercial, acadêmico, político e financeiro entre as partes.

\section{REFERÊNCIAS}

As referências marcadas com o símbolo * fizeram parte da revisão sistemática.

*Adami, M. J. (2009). O Projeto Ciência na Escola no cotidiano escolar: Uma prescrição ou uma contribuição aos professores? (Dissertação de mestrado). Faculdade de Educação da Universidade Estadual de Campinas, Campinas.

Aguiar, W. M. J., \& Ozella, S. (2013). Núcleos de significação: Aprimorando a proposta dos núcleos de significação. Revista Brasileira de Estudos Pedagógicos, 94(236), 299-322. http://dx.doi.org/10.1590/198053142818. 
Aliane, P. P., Mamede, M. V., \& Furtado, E. F. (2011). Revisão sistemática sobre fatores de risco associados à depressão pós-parto. Psicologia em Pesquisa, 5(2), 146-155. Recuperado em 28 de maio de 2019, de http://pepsic.bvsalud.org/scielo.php?script=sci arttext\&pid=S1982$12472011000200007 \&$ lng = pt\&tlng=pt.

*Alvarenga, C. F. (2008). Relações de gênero e trabalho docente: Jornadas e ritmos no cotidiano de professoras e professores. (Dissertação de mestrado). Programa de Pós-Graduação em Educação da Faculdade de Educação da Universidade de São Paulo, São Paulo.

*Annibal, S. F. (2009). Aspectos mediadores e a identidade docente na sociedade contemporânea: O contexto do ensino de língua portuguesa. (Tese de doutorado). Programa de Pós-Graduação em Educação da Universidade Estadual Paulista, Marília.

*Aragão, M., \& Freitas, A. G. B. de (2012). Práticas des castigos escolares: Enlaces históricos entre normas e cotidiano. Conjectura, 17(2), 17-36. Recuperado em 28 de maio de 2019, de http://www.ucs.br/etc/revistas/index.php/conjectura/article/view/1648/102 4.

Azanha, J. M. P. (1992). Uma Idéia de Pesquisa Educacional. São Paulo, SP: Editora da Universidade de São Paulo.

Bell, J. (2008). Projeto de pesquisa: Guia para pesquisadores iniciantes em educação, saúde e ciências sociais. ( $4^{a}$ ed). Porto Alegre, RS: Artmed.

Berger, P. L., \& Luckmann, T. (2011) Os fundamentos do conhecimento na vida cotidiana. In: P. L. Berger, \& T. Luckmann, A construção social da realidade. (33a ed). Petrópolis, Vozes.

*Bezerra, B. S. (2009). Saberes docentes no cotidiano escolar: Uma análise no cenário dos ciclos e da progressão continuada. (Dissertação de mestrado). Faculdade de Educação da Universidade de São Paulo, São Paulo.

*Camargo, P. E. B. de (2013). No compartilhar das palavras: Experiências de um professor de Geografia. (Tese de doutorado). Programa de Pós-Graduação em Geografia da Universidade Estadual Paulista, Rio Claro.

*Carreri, A. V. (2007). Cotidiano escolar e políticas curriculares: Táticas entre professores consumidores. (Dissertação de mestrado). Faculdade de Educação da Universidade Estadual de Campinas, Campinas.

Certeau, M. de. (2008). A invenção do Cotidiano: 1. Artes de Fazer (15a ed). Petrópolis, RJ: Vozes.

*Corrêa, R. M. (2009). Na escuta: Encontros e diálogos dos/com os professores sobre os dilemas do cotidiano escolar. (Tese de doutorado). Faculdade de Educação da Universidade Estadual de Campinas, Campinas.

Coutinho, M. C., Oliveira, F., \& Sato, L. (2016). Olhar o cotidiano: Percursos para uma psicologia social do trabalho. Psicologia USP, 27(2), 130-136. doi: 10.1590/0103-656420140053. 
Duran, M. C. G. (2007). Maneiras de pensar o cotidiano com Michel de Certeau. Diálogo Educacional, 7(22), 115-128. Recuperado em 28 de maio de 2019, de

https://periodicos.pucpr.br/index.php/dialogoeducacional/article/view/4177 $\angle 4096$.

*Guedes-Pinto, A. L., \& Fontana, R. A. C. (2006). Apontamentos teórico metodológicos sobre a prática de ensino na formação inicial. Educação em Revista, 44, 69-87. http://dx.doi.org/10.1590/S0102-46982006000200004.

Heller, A. (2014). Cotidiano e História. 10. ed. São Paulo, SP: Paz \& Terra.

*Horibe, A. C. B. (2012). Formação profissional e saberes docentes: Um estudo com professores da educação básica. (Dissertação de mestrado). Instituto de Psicologia da Universidade de São Paulo, São Paulo.

*Lara, A. F. L., Tanamachi, E. de R., \& Junior, J. L. (2006). Concepções de desenvolvimento e de aprendizagem no trabalho do professor. Psicologia em Estudo, 11(3), 473-482. http://dx.doi.org/10.1590/S141373722006000300003.

*Lopretti, T. A. P. (2007). A produção de saberes e conhecimentos no cotidiano escolar: Imagens de limites e possibilidades da ação educativa. (Dissertação de mestrado). Faculdade de Educação da Universidade Estadual de Campinas, Campinas.

*Luchese, T. Â., \& Grazziotin, L. S. (2015). Memórias de docentes leigas que atuaram no ensino rural da Região Colonial Italiana, Rio Grande do Sul (1930

- 1950). Educação e Pesquisa, 41(2), 341-358. http://dx.doi.org/10.1590/s1517-97022015041795.

Maffesoli, M. (1988). Conhecimento comum: Compêndio de sociologia compreensiva. (Trad. Aluizio Ramos Trinta). São Paulo, SP: Brasiliense.

Martins, J. S. (1998). O senso comum e a vida cotidiana. Tempo Social, 10(1), 18. http://dx.doi.org/10.1590/S0103-20701998000100001.

Martins, J. S. (2015). A sociabilidade do homem simples: Cotidiano e história na modernidade anômala. (3a ed). São Paulo, SP: Contexto.

*Mielke, P. E. (2010). Princípios da educação ambiental nas práticas e discursos de professores do ensino fundamental. (Dissertação de mestrado). Instituto de Biociências da Universidade Estadual Paulista Júlio de Mesquita Filho, Rio Claro.

*Oliveira, C. M. de S. (2012). As implicações da implementação do currículo oficial do Estado de São Paulo no cotidiano de uma escola. (Dissertação de mestrado). Programa de Pós-Graduação em Educação da Universidade Estadual Paulista Júlio de Mesquita Filho, Presidente Prudente.

Pais, J. M. (2009). Sociologia da vida quotidiana. (5a ed). Lisboa: ICS.

Patto, M. H. S. (1993). O conceito de cotidianidade em Agnes Heller e a pesquisa em educação. Perspectivas, 16, 119-141. Recuperado em 28 de maio de 2019, de https://periodicos.fclar.unesp.br/perspectivas/article/view/775/636. 
*Pierini, A. S. (2007). A (des)constituição da orientadora pedagógica na escola pública: Uma trama de muitos fios, vários laços e alguns nós. (Dissertação de mestrado). Faculdade de Educação da Universidade Estadual de Campinas, Campinas.

Pinto, A. L. G., \& Fontana, R. A. C. (2006). Apontamentos teórico-metodológicos sobre a prática de ensino na formação inicial. Educação em Revista, 44, 6987. http://dx.doi.org/10.1590/S0102-46982006000200004.

*Sene, D. G. A. (2010). Rotas alternativas: Histórias de professoras que não puderam cursar os Programas Especiais de Formação Pedagógica Superior em São Paulo. (Dissertação de mestrado). Faculdade de Educação da Universidade de São Paulo, São Paulo.

Sato, L., \& Souza, M. P. R. (2001). Contribuindo para desvelar a complexidade do cotidiano através da pesquisa etnográfica em psicologia. Psicologia USP, 12(2), 29-47. http://dx.doi.org/10.1590/S0103-65642001000200003.

*Shiohara, A. (2009). O registro como mediação criadora de possibilidades. (Dissertação de mestrado). Faculdade de Educação da Universidade Estadual de Campinas, Campinas.

*Silva, J. R. (2012). Artes de fazer o ensino de história: Professor, aluno e livro didático entre os saberes admitido e inventivo. (Dissertação de mestrado). Programa de Pós-Graduação em História Social da Universidade Estadual de Londrina, Londrina.

*Silva, L. C. B. (2012). Práticas de usos da leitura e da escrita, situadas na esfera escolar, no âmbito do trabalho docente e da gestão educacional. (Tese de doutorado). Faculdade de Educação da Universidade Estadual de Campinas, Campinas.

*Silva, M. U. (2008). Avaliação formativa e reflexão pedagógica de um grupo de professores do ensino fundamental II - pesquisa-ação. (Tese de doutorado). Faculdade de Filosofia e Ciências da Universidade Estadual Paulista Júlio de Mesquita Filho, Marília.

Spink, P. K. (2008). O pesquisador conversador no cotidiano. Psicologia \& Sociedade, 20, 70-77. http://dx.doi.org/10.1590/S010271822008000400010.

Tedesco, J. C. (1999). Paradigmas do cotidiano: Introdução à constituição de um campo de análise social. (2a ed). Passo Fundo, RS: UPF.

Zago, N. (2003). A entrevista e seu processo de construção: Reflexões com base na experiência prática de pesquisa. In N. Zago, M. P. Carvalho, \& R. A. T. Vilela (Eds.), Itinerários de pesquisa: Perspectivas qualitativas em Sociologia da Educação (pp. 287-309). Rio de Janeiro, RJ: DP\&A.

*Zibetti, M. L. T., \& Souza, M. P. R. (2010). A dimensão criadora no trabalho docente: Subsídios para a formação de professores alfabetizadores. Educação e Pesquisa, 36(2), 459-473. http://dx.doi.org/10.1590/S151797022010000200003. 
Sobre as autoras

Andreia Martins é doutoranda do Programa de Pós-Graduação em Psicologia da Universidade Federal de Santa Catarina (UFSC) e Bolsista UNIEDU/FUMDES. Possui mestrado em Políticas Públicas e graduação em Psicologia. Integrante do Núcleo de Estudos sobre Trabalho e Constituição do Sujeito (NETCOS/UFSC). andreiacamposmartins76@gmail.com

Camila Trindade é mestranda pelo Programa de Pós-Graduação em Psicologia da Universidade Federal de Santa Catarina (UFSC). Psicóloga, graduada pela Universidade Federal do Rio Grande (FURG). Integrante do Núcleo de Estudos sobre Trabalho e Constituição do Sujeito (NETCOS/UFSC).

trindadecami@gmail.com

Maria Chalfin Coutinho é professora Titular Aposentada do Departamento de Psicologia e Professora Permanente do Programa de Pós-Graduação em Psicologia da Universidade Federal de Santa Catarina. Possui graduação em Psicologia (1981) e mestrado em Educação (1988) pela UFRGS e Doutorado em Ciências Sociais (2000) pela UNICAMP. Realizou estudos pós-doutorais junto ao Programa de Pós-Graduação em Psicologia Social da USP (2010/2011). Bolsista Produtividade pelo CNPq. maria.chalfin@ufsc.br

Certificamos que todas as autoras participaram suficientemente do trabalho para tornar pública sua responsabilidade pelo conteúdo. Conceitualização, investigação e visualização do artigo: Andreia Martins, Camila Trindade e Maria Chalfin Coutinho. Fizeram a redação inicial do artigo (rascunho): Andreia Martins e Camila Trindade. Responsável pela redação final (revisão): Maria Chalfin Coutinho. Responsável pela edição final (edição): Andreia Martins, Camila Trindade e Maria Chalfin Coutinho.

As autoras agradecem ao Programa de Bolsas de Pós-Graduação de Santa Catarina - UNIEDU, à Coordenação de Aperfeiçoamento de Pessoal de Nível Superior - CAPES - e ao Conselho Nacional de Desenvolvimento Científico e Tecnológico - CNPq - pelo financiamento.

Recebido em: 16/02/2017 $1^{\text {a }}$ revisão em: 25/04/2017

Aceito em: 08/10/2017 